\title{
REVIEW ARTICLE OPEN Antibody therapies for the prevention and treatment of viral infections
}

\author{
Georgina Salazar ${ }^{1}$, Ningyan Zhang ${ }^{1}$, Tong-Ming Fu $\mathbb{D}^{2}$ and Zhiqiang $\mathrm{An}^{1}$
}

Antibodies are an important component in host immune responses to viral pathogens. Because of their unique maturation process, antibodies can evolve to be highly specific to viral antigens. Physicians and researchers have been relying on such high specificity in their quest to understand host-viral interaction and viral pathogenesis mechanisms and to find potential cures for viral infection and disease. With more than 60 recombinant monoclonal antibodies developed for human use in the last 20 years, monoclonal antibodies are now considered a viable therapeutic modality for infectious disease targets, including newly emerging viral pathogens such as Ebola representing heightened public health concerns, as well as pathogens that have long been known, such as human cytomegalovirus. Here, we summarize some recent advances in identification and characterization of monoclonal antibodies suitable as drug candidates for clinical evaluation, and review some promising candidates in the development pipeline.

npj Vaccines (2017)2:19; doi:10.1038/s41541-017-0019-3

\section{INTRODUCTION}

The earliest application of antibodies as a treatment for viral infections can be traced back to the early 20th century, use of sera from infected humans who had recovered from the same infection. ${ }^{1,2}$ This crude treatment regimen, serum therapy, was gradually replaced by antibodies purified from pooled sera, intravenous immune globulin (IVIG). ${ }^{3}$ Despite the success of both serum therapy and IVIG, no significant progress was made in the generation of antibodies as therapies until the hybridoma method was developed, enabling isolation of monoclonal antibodies (mAbs) from immunized mice in 1975. ${ }^{4}$ Since the mid-1980s, several methods have been developed for the efficient isolation of mAbs against viruses from human and animal sources. One method involves using an antigen to pan antibody libraries constructed from immunoglobulin $V_{H}$ and $V_{L}$ variable regions genes of non-immune, vaccinated, or naturally infected individuals. In this method, antibody libraries are presented to antigens by display, for instance on phage, ${ }^{5,6}$ bacteria, $^{7}$ yeast, ${ }^{8}$ or mammalian cells. ${ }^{9}$ In other methods, antibodies are cloned from single-memory $B$ cells ${ }^{10-13}$ or plasma $B$ cells ${ }^{14-16}$ isolated from vaccinated or naturally infected animals and human donors. mAbs have also been generated from immune sera using an approach that combines proteomics and reverse genetics. ${ }^{17,} 18$ More recently, heavy and light chain paired mAbs have been generated by deep sequencing of the B-cell IgG repertoire. ${ }^{19,20}$ This review focuses on approaches to generate therapeutic mAbs to fight viral infection, examples of mAb therapies for viral infections, and the challenges of developing such therapies.

Strategies for generation of therapeutic antibodies for viral infections

Phage displayed antibody libraries. mAbs can be isolated from immunized or infected humans or animals using a library of displayed antibodies (Fig. 1). Genes encoding the antibody heavy and light chains from B cells of immunized or infected humans or animals are cloned as Fab or scFv fragments and displayed, for instance on filamentous phage. Virus-specific antibodies are isolated by panning the libraries against antigens. This approach has been used to isolate potent neutralizing antibodies from the $B$ cells of rhesus macaques immunized with recombinant adenoviruses carrying a synthetic gene encoding hemagglutinin (HA) of the influenza virus ${ }^{6}$ and from human $\operatorname{lgM}^{+}$memory $B$ cells of recent seasonal influenza vaccines. ${ }^{5}$ In addition to panning libraries constructed from antibody repertoires following infection, panning of native antibody libraries has yielded potent neutralizing antibodies against viral infections. For example, a broadly neutralizing HIV antibody (D5) was isolated from panning a native antibody library. ${ }^{21}$ It might be difficult to identify highly neutralizing antibodies when panning against native phage libraries, because of the lack of antibody somatic hypermutation process. This disadvantage may be overcome by an in vitro affinity maturation step or by panning of libraries constructed from immunized or infected human or animal donors in which antibody somatic hypermutations took place against a given virus. While phage display is an efficient way to generate viral neutralizing antibodies from immunized, or infected, or non-immune humans or animals, the resulting antibodies do not necessarily represent the natural antibody repertoire, since the antibody fragments are generated from the random paring of IgG heavy and light variable regions. $^{22}$ Further, since a predefined and well-characterized antigen is required to pan the library, the approach is not suitable to identify new neutralizing epitopes of viral pathogens. ${ }^{22}$

Single-memory $B$ cells. The ability to clone antibody encoding genes from single $B$ cells of naturally infected or immunized individuals is a significant advance in isolating anti-viral mAbs. Three different approaches have been developed for the isolation of mAbs from single-memory B cells (Fig. 2). One approach involves isolating memory $B$ cells specific for viral antigens by flow

\footnotetext{
${ }^{1}$ Texas Therapeutics Institute, Brown Foundation Institute of Molecular Medicine, The University of Texas Health Science Center at Houston, Houston, TX, USA and ${ }^{2}$ Merck Research Laboratories, Merck and Co., Inc., Kenilworth, NJ, USA

Correspondence: Zhiqiang An (ZhiqiangAn@uth.tmc.edu)
}

Received: 2 February 2017 Revised: 8 May 2017 Accepted: 16 May 2017

Published online: 10 July 2017 


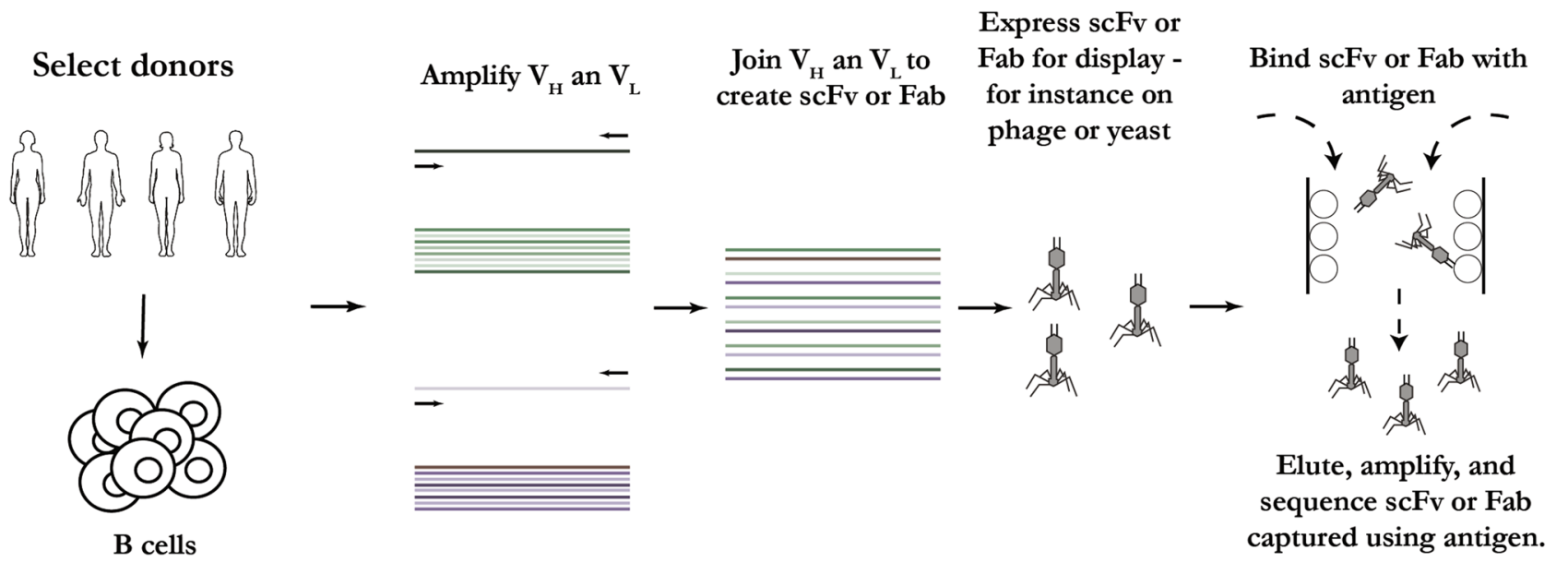

Fig. 1 Schematic representation of generation of mAbs using phage display. This method has the advantage of being relatively easy with the potential to generate $\mathrm{VH}$ and VL combinations not found in nature. The diagram was generated based on a combination of publications ${ }^{6,21}$

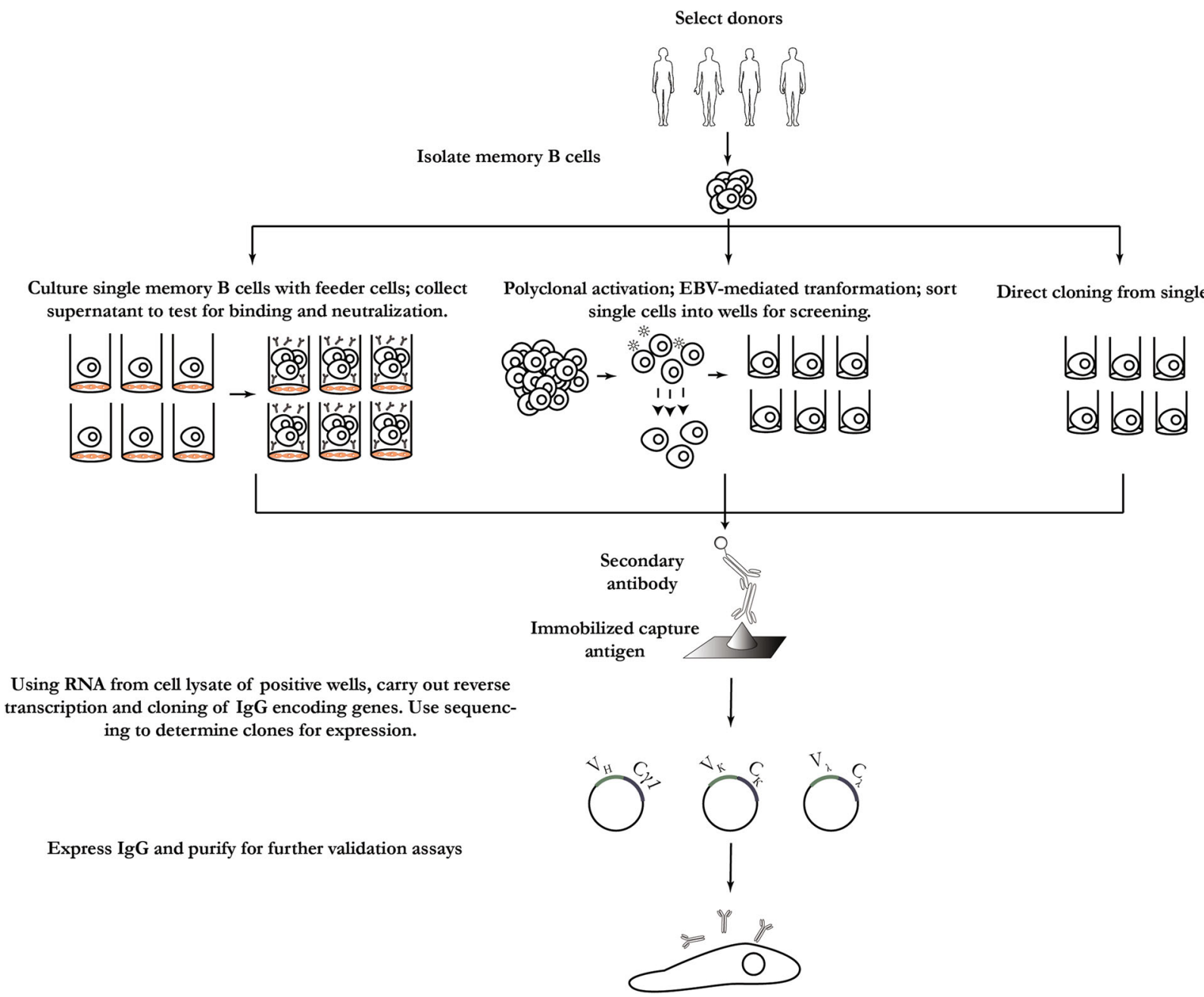

Fig. 2 Schematic of isolation of mAbs from memory B cells. When these cells producing antibodies with desired characteristics can be found, a supply of these antibodies can be maintained by culture and cloning, immortalization, or direct cloning. The diagram was generated by summarizing multiple published papers. The diagram was generated based on a combination of publications ${ }^{10-13,22-27}$

cytometry, followed by direct cloning of the antibody-encoding genes without culturing of the B cells. This approach has been applied to isolate neutralizing antibodies from naturally infected and immunized human donors for $\mathrm{Zika}^{23}$ respiratory syncytial virus (RSV), ${ }^{24} \mathrm{HIV}^{12}$ and HPV. ${ }^{25}$ Antibodies were also isolated through this method from antigen-specific individual memory $B$ cells of rhesus macaques immunized with gp140-F trimers based on the HIV-1 YU2 isolate. ${ }^{26}$ 
Since predefined antigens are required to identify the memory $B$ cells then isolated by flow cytometry sorting, the abovementioned approach is not suitable for identification of novel neutralizing targets. To identify novel target epitopes, first, a large number of memory B cells are cultured, and then, the culture supernatant is screened against various antigens. This approach has been used for the discovery of broad and potent neutralizing antibodies against HIV and the discovery of a new HIV-1 vaccine target. ${ }^{11}$ In this work, ${ }^{11}$ surface lgG-expressing memory B cells were enriched from peripheral blood mononuclear cells (PBMCs) of a HIV-1 infected donor by negative depletion with antibodies to CD3, CD14, CD16, IgM, IgA, IgD on magnetic beads. Individual memory $B$ cells were then seeded in microtiterplates in the presence of feeder cells and conditioned media generated from mitogen-stimulated human $\mathrm{T}$ cells from healthy donors. The supernatants were collected 8 days later and screened for antigenbinding reactivity. In another protocol, the addition of cytokines interleukin (IL)-2, IL-21, and irradiated 3T3-msCD40L feeder cells can successfully stimulate memory $B$ cells to produce high concentrations of IgG in the supernatant in 2 weeks. ${ }^{10}$

In a third approach, B cells are immortalized by Epstein-Barr Virus (EBV) in the presence of a toll-like receptor. This approach has been applied to the isolation of neutralizing antibodies against rabies, SARS-CoV, and other viruses. ${ }^{13,22,27}$

Single-antibody-secreting plasma $B$ cells. It has been reported that antigen-specific plasma cells account for up to $40-90 \%$ of total lgG-secreting cells in peripheral blood one week after boost immunization. ${ }^{28}$ Methods for cloning IgG from human antibodysecreting cells have been developed (Fig. 3). ${ }^{15,29-32}$ This approach has been applied for isolating neutralizing antibodies from naturally infected and immunized human donors for dengue ${ }^{33}$ and H1N1 influenza. ${ }^{15,} 34$ Protocols for cloning mAbs from nonhuman primate plasma and memory $B$ cells have also been reported. ${ }^{16,35,36}$ In one report, a large panel of dengue targeting $\mathrm{mAbs}$ were cloned from single-antibody-secreting B cells of a rhesus macaque immunized with an experimental vaccine. ${ }^{16}$ Single-antibody-secreting $B$ cells were identified and isolated by flow cytometry, using a panel of phenotype markers. ${ }^{16}$ To interrogate a large number of plasma B cells, a method was developed using microwell array chips. This method enables the analysis of live cells on a single-cell basis and offers rapid, efficient, and high-throughput (up to 234,000 individual cells) identification of antibody-secreting plasma cells. ${ }^{37}$

plasma B cells
synthesis and two
rounds PCR - amplify
$\mathrm{V}_{\mathrm{H}}, \mathrm{V}_{\mathrm{K}}, \mathrm{V}_{\lambda}$

Sort single cells to 96-well plate for cDNA unds PCR - amplify $\mathrm{V}_{\mathrm{H}}, \mathrm{V}_{\mathrm{K}}, \mathrm{V}_{\lambda}$
In addition to direct cloning of antibody encoding genes from plasma $B$ cells, single plasma cells can also be cultured on a monolayer of immortalized stromal cells or with IL-6 stimulation; the cultured cells would be able to produce enough antibody for screening assays of parallel viral binding and neutralization for identifying rare antibodies. ${ }^{29}$

Proteomics-directed cloning of mAbs from serum. Antibodies cloned from single memory or plasma B cells represent the genetic antibody repertoire of an individual at a given time in response to a specific viral infection. However, this repertoire does not necessarily correspond to that of the antibodies present in circulation. Protocols have been developed to identify antigenspecific antibody sequences directly from circulating polyclonal antibodies in the sera of immunized or naturally infected animals or humans (Fig. 4). These protocols combine the power of proteomics and next-generation sequencing (NGS). ${ }^{17,} 18,38,39$ The approach involves affinity purification of antibodies with antigen specificity followed by analysis of proteolytically digested antibody fractions by liquid chromatography-mass spectrometry. Peptide spectral matches of antibody variable regions are obtained by searching a reference database created by NGS of the B-cell immunoglobulin repertoire of the immunized animal or human. Finally, heavy and light chain sequences are paired and expressed as recombinant mAbs. ${ }^{17,18,38}$ Using this approach, mAbs targeting HBV and human cytomegalovirus (HCMV) were cloned from human donors. ${ }^{38}$ This approach provides an alternative method to isolate potent viral neutralizing antibodies for therapeutic purposes. Further, it promotes a deeper understanding of the humoral response.

Deep sequencing of paired antibodies encoding genes from $B$ cells. While cloning mAbs from individual memory or plasma $B$ cells is a robust and efficient approach to isolate viral-specific antibodies, the approach provides only a snapshot and sample of the antibody genetic repertoire of an individual at a given time against a particular virus. Various deep-sequencing approaches can provide an unbiased picture of the B-cell repertoire based on either its heavy chain or light chain information, but the endogenous pairing of heavy and light chain is lost after bulk lysis of B-cell populations. ${ }^{40}$ Phylogenetic matching of heavy and light chains from antibody deep-sequencing data can provide an approximation of natural heavy and light chain pairing. ${ }^{41}$ Highthroughput sequencing of paired heavy and light chain variable

\section{Clone IgG and \\ sequence to determine \\ correct clones for \\ Express IgG and purify for further validation assays} expression

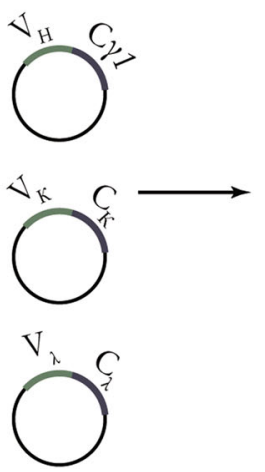

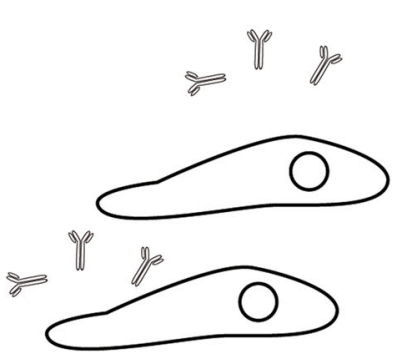

Fig. 3 Overview of isolation, culture, and antibody gene cloning from plasma B cells. This method can be an efficient way of generating antibodies with desired specificity given the right antigen bait and timing. The diagram was generated based on a combination of publications ${ }^{15}, 16,28-37$ 


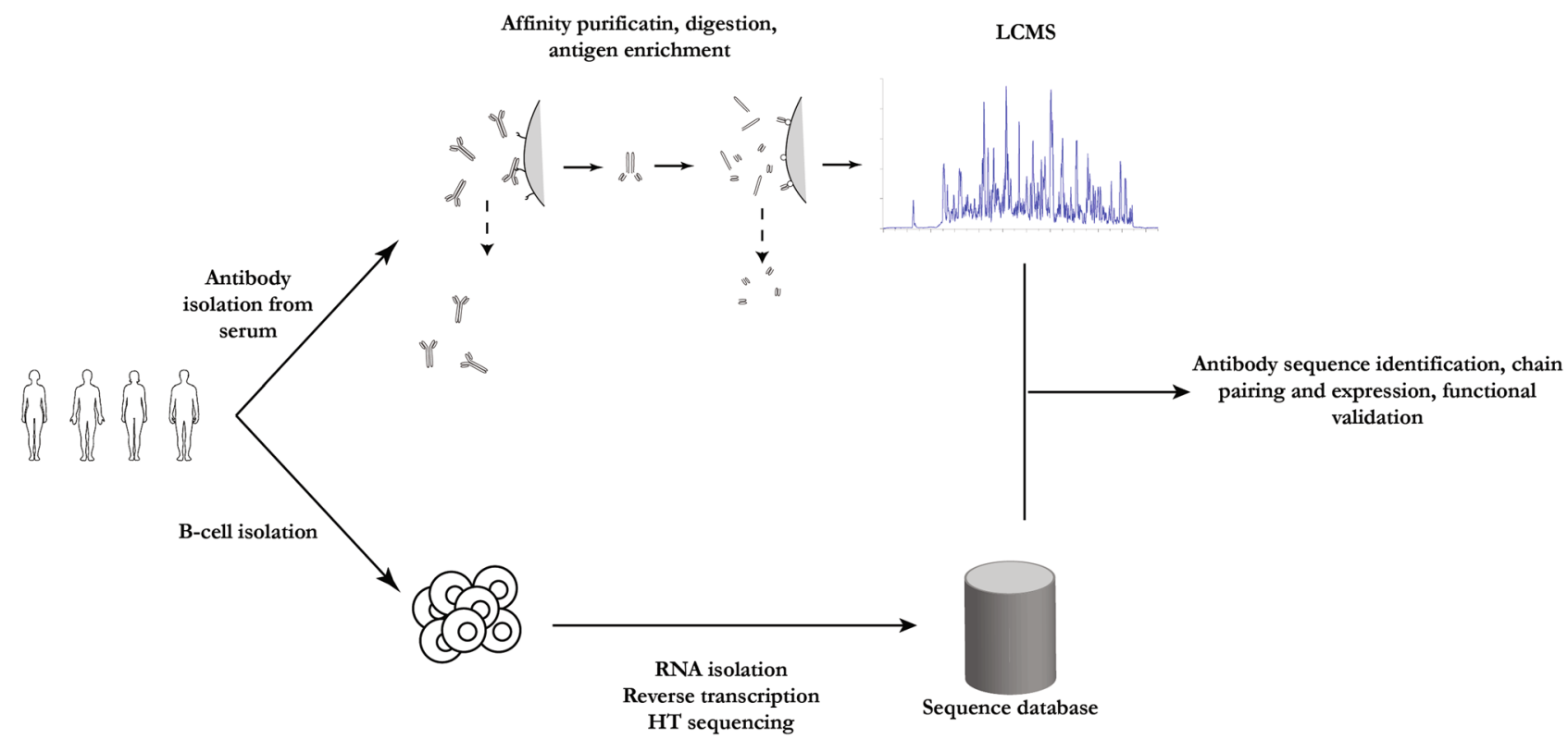

Fig. 4 Representation of the combination of proteomics and high-throughput sequencing approaches to isolation of relevant mAbs from human donors. Analysis of nucleic acids from B cells combined with proteomic analysis of antibodies in serum provides a deeper understanding of the humoral response to viral infection and vaccinations. The diagram was generated based on a combination of publications $^{19}, 18,38,39$

regions at the single-cell level has proven technically challenging. A method that allows the determination of a paired heavy and light chain variable region repertoire from millions of cells with high precision was recently reported. ${ }^{19,} 20,42$ Briefly, flow-focusing is used to encapsulate single cells in emulsions containing magnetic beads for messenger RNA (mRNA) capture. The mRNA transcripts are then reverse-transcribed, physically linked to their partners by overlap extension PCR, and interrogated by highthroughput paired-end sequencing. ${ }^{19}$ Once adapted widely by the research community, this method will provide powerful information on antibody response to infection and vaccination, vaccine efficacy, and the cloning of potent viral neutralizing antibodies. ${ }^{42}$

mAbs targeting viral infections

Table 1 shows mAbs in clinical development for the prevention and treatment of infectious viral diseases. These mAbs have been isolated from a variety of non-immune and immune sources, human and animal donors, using the range of strategies for generation of therapeutic antibodies introduced above.

Human cytomegalovirus. HCMV is a member of the herpes family. Like other members of this family, HCMV can establish lifelong latent infection in its host, with occasional reactivation. ${ }^{43}$ Infection is in general asymptomatic, but can cause serious disease in people whose immune systems are compromised, such as transplant recipients and AIDS patients with HIV infection. Furthermore, children infected with HCMV in utero are at risk for serious birth defects. They may even experience delayed hearing loss and deafness despite being asymptomatic at birth. ${ }^{43}$ After several decades of effort, an effective vaccine against HCMV infection remains elusive. ${ }^{44}$

Typical adult therapy for HCMV infection is with antivirals such as ganciclovir, foscarnet, and cidofovir. ${ }^{45}$ For children who are suspected to have been infected in utero, treatment with Ganciclovir may prevent developmental problems and loss of hearing. ${ }^{46}$ Women with primary infection during pregnancy, a risk factor for congenital HCMV infection and disease (cHCMV), may be treated with $\mathrm{HCMV}$ immunoglobulin as a way to reduce the $\mathrm{CHCMV}$ risk. $^{47}$ Polyclonal preparations of antibodies (IVIGs) are an alternative for antiviral medications that have serious limitations. For example, IVIGs are difficult to standardize and less effective. In contrast, mAbs specifically targeting key epitopes should provide an advantage in efficacy. Multiple HCMV targeting mAbs being developed are in various stages of preclinical and clinical trials. ${ }^{48,} 49$

HCMV is a complex virus with multiple antigens, including glycoprotein $\mathrm{B}(\mathrm{gB})$ and the $\mathrm{gHp}$ entameric complex. ${ }^{43}, 50$ The vast majority of antibodies generated against HCMV target its gB antigen. The $\mathrm{gB}$ targeting antibodies alone may not have strong neutralizing ability to control HCMV infection and reactivation. ${ }^{51}$ Recent studies have demonstrated that the pentameric $\mathrm{gH}$ complex is the primary target for neutralizing antiviral antibodies, ${ }^{50}$ and as result most recently developed mAbs target the virus' pentameric complex. ${ }^{51}$ The use of a combination of mAbs has several advantages, including enhanced efficacy and decreased development of viral resistance. At least two of the HCMV targeting antibodies in clinical trials are combinations of two mAbs. ${ }^{48,} 49$

CSJ148: CSJ148 is a combination of two anti-HCMV human mAbs -LJP538, which binds to the viral gB protein and LJP539, which binds to the viral $\mathrm{gH}$ pentameric complex. ${ }^{48}$ LJP538, also known as $7 \mathrm{H} 3$, and LJP539, as 4I22, were isolated from EBV immortalized B cells from HCMV-immune human donors as described. ${ }^{52,53}$ Results from clinical trials show CSJ148 and its component mAbs were safe and well tolerated, with pharmacokinetics as expected for human immunoglobulin. ${ }^{48}$ Phase 2 clinical trials of CSJ148 in stem cell transplant patients are ongoing. ${ }^{54}$

RG7667: RG7667 is a combination of two mAbs, MCMV5322A and MCMV3068A. ${ }^{49}$ MCMV5322A is an affinity-matured version of MSL-109 that binds a neutralizing epitope on $\mathrm{HCMVgH} / \mathrm{gL} .{ }^{55} \mathrm{MSL}-$ 109 is a human mAb isolated from spleen cells of a HCMV seropositive individual. In the late 1990s, MSL-109, known by several other names including Protovir, SDZ 89-109, SDZ MSL-109, and Sevirumab, was developed by Sandoz in several clinical trials as a therapy for HCMV infection. ${ }^{56}$ Development was discontinued after MSL-109 failed to demonstrate improved outcomes in the treatment of HCMV retinitis in AIDS patients and prevention of $\mathrm{HCMV}$ infection after hematopoietic stem cell transplantation. ${ }^{56}$ In addition to the activities in developing MSL-109 as a therapy, the antibody was a subject for a series of mechanistic studies, 
including some that defined the mechanism by which HCMV escapes neutralization by MSL-10957. The other component of RG7667, MCMV3068A, binds the pentameric $\mathrm{gH}$ complex. MCMV3068A was isolated from a mouse hybridoma and subsequently humanized. ${ }^{49}$

RG7667 is developed by Genentech as a treatment to prevent HCMV infection in utero and in solid organ and hematopoietic stem cell transplant recipients. Phase 1 studies of RG7667 showed to be safe and well-tolerated and had a favorable pharmacokinetic and immunogenicity profile. The study supports further development of RG7667 as a therapy for the prevention and treatment of HCMV infection in susceptible populations. ${ }^{49}$ In a Phase 2 trial in high-risk kidney transplant recipients, RG7667 was well tolerated, numerically reduced the incidence of HCMV infection within 12 and 24 weeks post-transplantation; it was statistically significant for delaying time to HCMV viremia, and was associated with few cases of HCMV disease compared to placebo. $^{58}$

Influenza. Influenza virus infections are common and usually cause only mild illness. Typical therapy involves respiratory precautions and medication such as oseltamivir (Tamiflu), that inhibit the influenza protein neuraminidase involved in release of virus particles. However, development of resistance to neuraminidase inhibitors is a problem. ${ }^{59}$ Influenza viruses have a unique flexibility which tolerates small errors, resulting in a change of viral structure known as "antigenic drift" that allows escape of the immune response. ${ }^{60}$ The seasonal flu vaccine protects against the influenza viruses that are predicted to be most common during the upcoming season. However, the vaccine is not always effective, due to mismatch of the predicted strains with the actual circulating flu strains. A universal flu vaccine with long-term effectiveness remains elusive. ${ }^{61}$ Occasionally influenza virus makes a major change that preserves its virulence, as in the case of the 2009 pandemic H1N1 strain. ${ }^{34}$ The large antigenic drift renders the seasonal flu vaccine of little efficacy. As a result of the rapid development of antibody isolation and engineering technologies, passive immunization with broadly neutralizing antibodies is becoming an increasingly viable approach to address the immediate health threat of an influenza pandemic while vaccines are being developed.

MHAA4549A: MAb MHAA4549A, also known as 39.29, was cloned from a single-human plasmablast cell isolated from an influenza vaccinated donor. MHAA4549A binds a highly conserved epitope on the stalk of influenza A HA and blocks the HAmediated membrane fusion in the endosome, and is capable of neutralizing all known human influenza A strains. ${ }^{62}$ In two Phase 1 clinical trials, MHAA4549A was safe and well tolerated up to a single intravenous dose of $10,800 \mathrm{mg}$. The mAb demonstrates linear serum pharmacokinetics consistent with those of a human IgG1 antibody lacking known endogenous targets in humans. ${ }^{63}$ MHAA4549A is currently in Phase 2 clinical trials for the treatment of patients hospitalized with severe influenza $A$ infection. ${ }^{64,} 65$

VIS410: VIS410 is an engineered human $\operatorname{lgG} 1 \mathrm{mAb}$, which targets the stem (or stalk) region of influenza A HA and has demonstrated binding to both group 1 and group 2 HAs of influenza A viruses. ${ }^{66}$ Prophylactic administration of VIS410 resulted in the complete protection of mice from developing acute respiratory distress syndrome against lethal influenza A (H7N9) virus challenge. ${ }^{67}$ In a Phase 1 clinical trial, VIS410 was safe and well tolerated and had good relative exposure in both serum and upper respiratory tract. These results support its use as either a single-dose therapeutic or prophylactic for influenza A. ${ }^{68}$ VIS410 is currently in a Phase $2 a$ study designed to assess the safety and tolerability of the antibody in subjects with uncomplicated influenza. ${ }^{69}$

CR6261: Isolated from combinatorial display libraries that were constructed from human $\operatorname{lgM}(+)$ memory $B$ cells of seasonal influenza vaccinees, antibody CR6261 neutralizes the virus by blocking conformational rearrangements associated with membrane fusion. The antibody is protective in mice when given before and after lethal $\mathrm{H} 5 \mathrm{~N} 1$ or $\mathrm{H} 1 \mathrm{~N} 1$ challenge. ${ }^{5}$ CR6261 recognizes a highly conserved helical region in the membraneproximal stem of HA1 and HA2. The antibody neutralizes the virus by blocking conformational rearrangements associated with membrane fusion. ${ }^{70}$ CR6261 is currently in Phase 2 clinical testing. $^{71}$

CR8020: The human mAb CR8020 has broad neutralizing activity against most group 2 viruses, including H3N2 and H7N7, which cause severe human infection. CR8020 was isolated from a B cell of a donor vaccinated against influenza. ${ }^{72}$ The crystal structure of Fab CR8020 with the 1968 pandemic H3 HA reveals a highly conserved epitope in the HA stalk distinct from the epitope recognized by the $\mathrm{V}(\mathrm{H}) 1-69$ group 1 antibodies. ${ }^{72}$ CR8020 has been tested in Phase $1 / 2$ trials. $^{73}$ Structural and computational analyses indicate that $\mathrm{CR} 8020$ targets HA residues that are prone to antigenic drift and host selection pressure. Critically, CR8020 escape mutation was seen in certain H7N9 viruses from recent outbreaks. $^{74}$

TCN-032: Antibody TCN-032 was isolated from ab $\operatorname{lgG}(+)$ memory B cell of a healthy human subject. The antibody recognizes a previously unknown conformational epitope within the ectodomain of the influenza matrix 2 protein, M2e. ${ }^{75}$ This antibody-binding region is highly conserved in influenza $A$ viruses. The region is present in nearly all strains detected to date, including highly pathogenic viruses that infect primarily birds and swine and the 2009 swine-origin H1N1 pandemic strain (S-OIV). In addition, TCN-032 protected mice from lethal challenges with either $\mathrm{H} 5 \mathrm{~N} 1$ or $\mathrm{H} 1 \mathrm{~N} 1$ influenza viruses. ${ }^{75}$ A Phase 1 clinical study showed that TCN-032 was safe, with no evidence of immune exacerbation based on serum cytokine expression. The trial also showed that the antibody may provide immediate immunity and therapeutic benefit in influenza A infection, with no apparent emergence of resistant virus. ${ }^{76}$

Human immunodeficiency virus. Despite decades of intensive effort, an effective HIV vaccine remains a challenge. With recent advances in the identification of broadly neutralizing antibodies from single memory B cells of infected individuals, anti-HIV antibodies are becoming a viable approach for both prophylactic and therapeutic treatment of HIV infection and AIDS. ${ }^{77}$ A number of broadly HIV-1 neutralizing antibodies are currently in clinical development to assess their therapeutic benefit in passive immunization. Most of the HIV mAbs in clinical testing, for instance VRC01, 3BNC117, 10-1074, and 4E10, are broadly neutralizing on the basis of targeting conserved viral epitopes. ${ }^{78}$ PRO 140 is an antibody used to treat HIV targeting host CCR5, which often acts with CD4 as a co-receptor for the virus. ${ }^{79}$ Many excellent reviews provide more detail on broadly neutralizing antibodies against HIV. ${ }^{77,}{ }^{80-82}$ Here we highlight some examples of HIV targeting antibodies in clinical development.

VRC01: VRC01 is a broadly neutralizing HIV-1 mAb isolated from the $B$ cells of an HIV-infected patient. ${ }^{40,83}$ It is directed against the HIV-1 CD4-binding site and is capable of potently neutralizing diverse HIV-1 strains. ${ }^{84}$ A Phase 1 study showed that the antibody was safe and demonstrated expected half-life and pharmacokinetics for a human $\operatorname{lgG}{ }^{85}$ In two open-label trials of the safety, side-effect profile, pharmacokinetic properties, the antiviral activity of VRC01 was tested in persons with HIV infection who were undergoing ART (antiretroviral therapy) interruption. The antibody slightly delayed plasma viral rebound in the trial participants as compared with historical controls, but did not maintain viral suppression through week $8^{86}$ VRC01 is being tested in multiple Phase 2 trials. $^{87-89}$

3BNC117: Human antibody 3BNC117was isolated from single B cells of a patient with high titers of broadly neutralizing 
Table 1. Antibody therapies in clinical trials for the prevention and treatment of viral infections

\begin{tabular}{|c|c|c|}
\hline Virus & MAb, sponsor & Notes \\
\hline \multirow[t]{2}{*}{ HCMV } & CSJ148 (LJP538 and LJP539), Novartis & $\begin{array}{l}\text { CSJ148 is a combination of two anti-HCMV human mAbs that bind to and } \\
\text { inhibit the function of viral HCMV gB (LJP538) and pentameric gH } \\
\text { complex (LJP539). The two antibodies were isolated from EBV } \\
\text { immortalized B cells. CSJ148 is in Phase } 2 \text { clinical trials (NCT02268526) }\end{array}$ \\
\hline & $\begin{array}{l}\text { RG7667 (MCMV5322A and } \\
\text { MCMV3068A), Genentech }\end{array}$ & 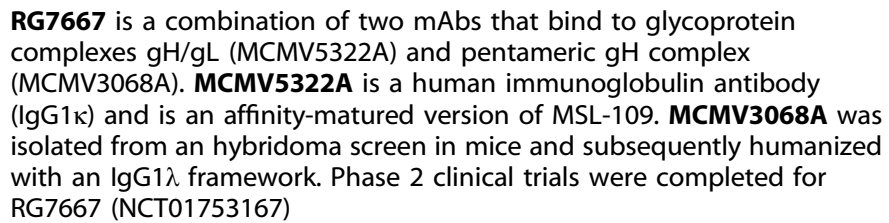 \\
\hline & TCN-202, Theraclone Sciences & TCN-202 is a human mAb that targets AD-2, a linear, conserved, poorly \\
\hline
\end{tabular}

TCN-202, Theraclone Sciences

MSL-109/Serivumab, NCRR, NIAID, Facet Biotech, Johns Hopkings Bloomberg School of Public Health, Sandoz Inc.

Influenza MHAA4549A (earlier known as 39.29), Genentech, Inc.

VIS410, Visterra, Inc.

CR6261, Crucell Holland BV and the National Institute of Allergy and Infectious Diseases (NIAID)

CR8020, Crucell Holland BV and Retroscreen Virology Ltd.

TCN-032, Theraclone Sciences

VRC01, NIAID

3BNC117, Rockefeller University, Weill Medical College of Cornell University, Brigham and Women's Hospital, and the University of Cologne

10-1074, Rockefeller University and the University of Cologne

4E10, 2F5, 2G12, Rockefeller University

PRO 140, Amarex Clinical Research, CytoDyn, Inc., National Institute on immunogenic epitope on the N-terminal domain of HCMV gB. This mAb effectively neutralized infection and was observed to be well tolerated and non-immunogenic in initial clinical trials. However, development was discontinued after a Phase 1 adverse event (NCT01594437)

MSL-109 is a human monoclonal lgG isolated from a HCMV seropositive individual that recognizes the viral glycoprotein $\mathrm{H}(\mathrm{gH})$. A Phase $2 / 3$ trial of MSL 109 was completed (NCT00000836)

MHAA4549A is a human immunoglobulin $\mathrm{G} 1$ (IgG1) mAb that binds to a highly conserved epitope on the stalk of Group 1 and Group 2 influenza $A$ hemagglutinins and blocks the hemagglutinin-mediated membrane fusion in the endosome, neutralizing all known human influenza $A$ strains. MHAA4549A was cloned from a single human plasmablast cell isolated from an influenza vaccinated donor MHAA4549A is in Phase 2 clinical trials (NCT02623322)

VIS410 targets a conserved epitope in the stem of influenza A hemagglutinin (HA). It was engineered using structural information on antibody-antigen interfaces. VIS410 is in Phase 2 clinical trials (NCT02989194)

Isolated from a healthy, vaccinated individual using phage display selection on recombinant $\mathrm{H} 5 \mathrm{HA}$, mAb CR6261 targets a highly conserved helical region in the membrane-proximal stem of HA1/HA2 from 1918 H1N1 influenza and H5N1 influenza. It uses the Ig VH1-69 germline segment. CR6261 is in Phase 2 clinical trials (NCT02371668)

CR8020 is a broadly neutralizing influenza hemagglutinin stem-specific human mAb. CR8020 was isolated from a B cell of a donor vaccinated against influenza. A Phase 2 clinical trial was completed for CR8020 (NCT01938352)

One of a panel of mAbs derived from memory B cells of healthy human subjects, TCN-032 targets an epitope in the ectodomain of the influenza matrix 2 protein M2e. This epitope, first identified with the isolation of the panel of mAbs including TCN-032, is highly conserved in influenza A viruses. A Phase 2 clinical study was initiated for TCN-032 (NCT01719874) VRC01 is a broadly neutralizing antibody targeting the CD4-binding site of HIV gp120. It was isolated from memory B cells of infected individuals using a targeted flow cytometry-based approach. VRC01 is in multiple Phase 2 clinical trials (NCT02664415, NCT02568215, NCT02716675)

$3 B N C 117$ is a broad and potent neutralizing antibody against the CD4binding site of the HIV-1 Env protein. 3BNC117 is being tested in multiple Phase 2 clinical trials (NCT02446847, NCT02588586. NCT02850016)

Several antibodies including 10-1074 were isolated from $B$ cells from a clade A-infected African donor using YU-2 gp140 trimers as bait. 10-1074 is a broadly neutralizing antibody (bnAb) that targets the V3-glycan supersite of HIV gp120. 10-1074 is currently in multiple Phase 1 clinical trials in combination with 3BNC117 (NCT02825797, NCT02511990, NCT02825797)

4E10, 2F5, 2G12 are broadly and potently neutralizing mAb specific for gp41. A Phase $1 / 2$ clinical trial was completed for well-suppressed HAARTtreated individuals during acute and early HIV-1 infection (NCT00219986) PRO 140 is an antibody used to treat HIV targeting host CCR5 receptors. Pro 140 is in multiple Phase 2/3 trials (NCT02859961, NCT02355184,
Reference

52 


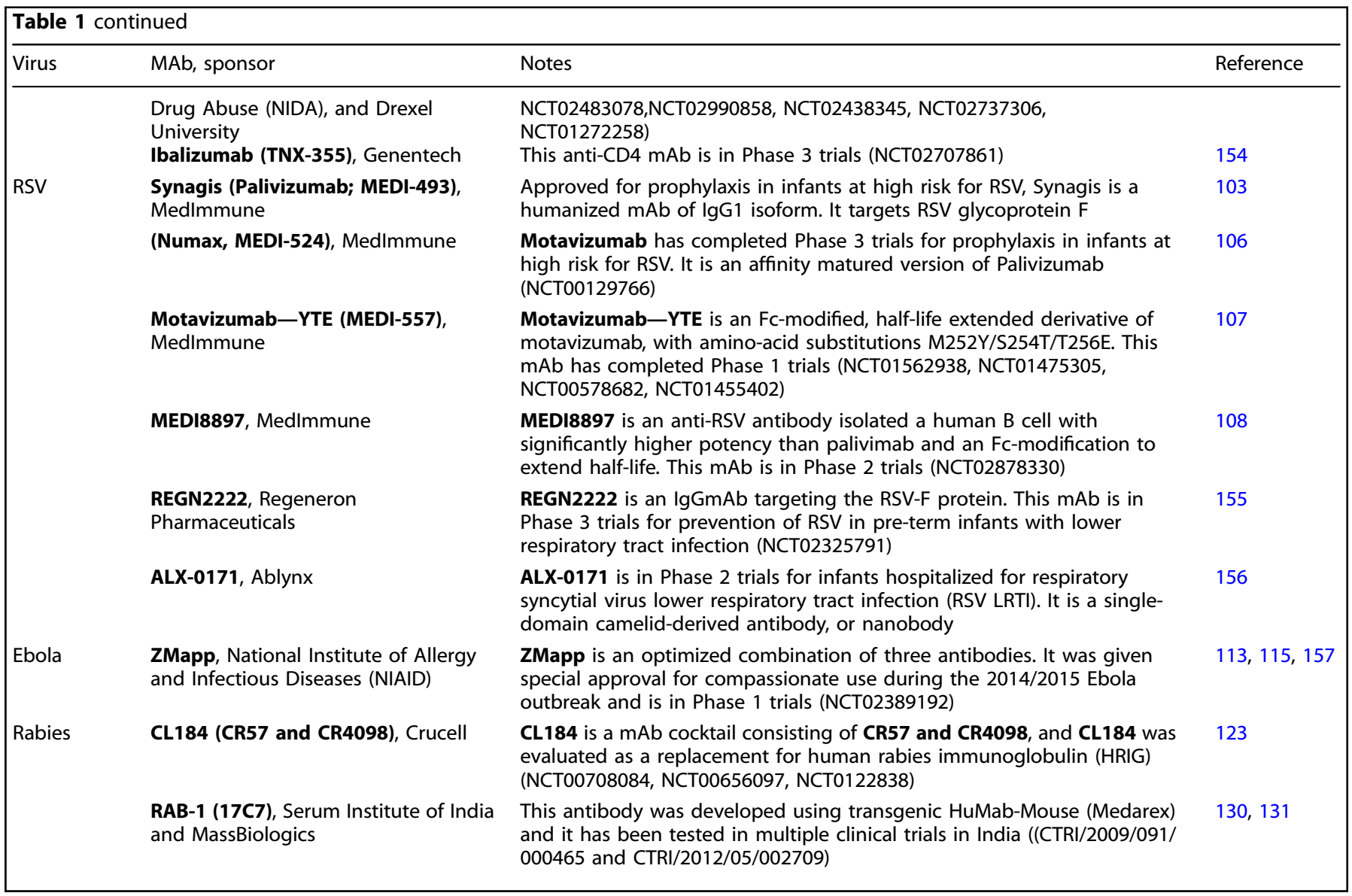

antibodies. This antibody binds to an HIV gp120 core glycoprotein stabilized in the CD4-bound conformation and lacking the variable (V) loops 1 to $3 .^{90}$ Antibody 3BNC117 blocked infection and suppressed viremia in macaques infected with the R5 tropic simian-human immunodeficiency virus (SHIV)-AD8, which emulates many of the pathogenic and immunogenic properties of HIV1 during infections of rhesus macaques. ${ }^{91}$ In Phase 1 trial, $3 \mathrm{BNC} 117$ is safe and effective in reducing HIV-1 viremia. ${ }^{92}$ In a Phase 2a trial, 3BNC117 suppresses viral rebound in humans during treatment interruption. The antibody exerts strong selective pressure on HIV-1 emerging from latent reservoirs during analytical treatment interruption in humans. ${ }^{93}$ In addition to suppressing viremia in HIV-1-infected individuals, 3BNC117 can enhance host humoral immunity to HIV-1 ${ }^{94}$. Antibody 3 BNC117 is also being tested in combination with a functionally similar broadly neutralizing antibody, 10-1074, in the treatment of HIV-1 infection. ${ }^{91,95,96}$

4E10, 2F5, and 2G12: Antibodies that recognize the highly conserved membrane proximal external region in the gp41 ectodomain stem of HIV such as 4E10, 2F5, and 2G12 have been tested in Phase $1 / 2$ trials in well-suppressed HAART-treated individuals treated during acute and early HIV-1 infection. ${ }^{97}$

Pro 140, Ibalizumab, and bispecific antibodies: In addition to antibodies directly targeting viral antigens to prevent and treat HIV-1 infection, antibodies targeting host receptors such as CCR5 and CD4 receptor are also being developed for HIV infection. For example, the CCR5 targeting humanized IgG4 mAb Pro 140 has been tested in clinical trials and the antibody exhibited potent, long-lived antiviral activity and was generally well tolerated. ${ }^{79,} 98,99$ Ibalizumab (iMab), a humanized mAb that binds to a conformational epitope on CD4 and blocks entry of HIV-1, is also being tested in clinical trials. ${ }^{100}$ In another approach, bispecific Abs that combine the HIV-1 inhibitory activity of ibalizumab with that of anti-gp120 bNAbs were constructed for passive immunization to prevent HIV-1 infection. ${ }^{101,} 102$

\section{Respiratory syncytial virus}

Palivizumab, motavizumab, and motavizumab-YTE: In 1998, the FDA approved palivizumab, which binds to the F glycoprotein of the RSV for prophylaxis in children susceptible to severe disease. $^{103,104}$ Motavizumab is an affinity matured derivative of palivizumab, tenfold more potent than palivizumab in $\mathrm{F}$ glycoprotein binding. ${ }^{103,} 105$ In Phase 3 clinical trials, motavizumab recipients had a $26 \%$ relative reduction in RSV hospitalization compared with palivizumab recipients, and motavizumab was superior to palivizumab for reduction of RSV-specific outpatient lower respiratory tract infections (MALRIs, 50\% relative reduction). ${ }^{106} \mathrm{~A}$ half-life extended derivative of the antibody, known as motavizumab-YTE (motavizumab with amino-acid substitutions $\mathrm{M} 252 \mathrm{Y} / \mathrm{S} 254 \mathrm{~T} / \mathrm{T} 256 \mathrm{E}$ [YTE]), an Fc-modified anti-RSV mAb was also tested in Phase 1 trials. ${ }^{107}$ Clearance of motavizumab-YTE was significantly lower (71 to $86 \%$ ) and the half-life was two to fourfold longer than that of motavizumab in healthy participants. ${ }^{107}$ The sustained serum concentrations of motavizumab-YTE were fully functional, as shown by RSV neutralizing activity that persisted for 240 days with motavizumab-YTE versus 90 days postdose for motavizumab. ${ }^{107}$ Despite the improvements of motavizumab and motavizumab-YTE over palivizumab, the clinical benefits were considered incremental and they have not been approved for clinical use.

MEDI8897, REGN2222, and ALX-0171: MEDI8897, which is 100fold more potent than palivizumab in vitro, is derived from D $25^{108}$ a mAb isolated from a $B$ cell of a human donor targeting the 
perfusion conformation of the RSV F protein. MEDI8897 was engineered with the YTE substitution within its Fc region for extended half-life. In a Phase 1 study, the mean half-life of MEDI8897 was 85 to 117 days across dose groups, and the safety profile of MEDI8897 was similar to placebo. ${ }^{108}$ MEDI8897 is currently in a Phase $2 \mathrm{~b}$ trial in healthy preterm infants who are between 29 and 35 weeks gestational age and entering their first RSV season. ${ }^{109}$ REGN2222, another human lgG mAb targeting the RSV-F protein is currently under Phase 3 clinical testing. ${ }^{110}$ Not an IgG1 antibody, ALX-0171 is a single-domain camelid-derived antibody, or nanobody, targeting the RSV-F protein. Due to small size of the nanobody, ALX-0171 is being tested as a therapeutic by inhalation in Phase 2 in infants (aged 1-24 months) who were hospitalized with an RSV infection. ${ }^{111}$

Ebola, Zika, rabies, and HBV. An outbreak of Ebola in West Africa between 2014 and 2015 affected 28,652 people and led to more than 11,325 deaths. ${ }^{112}$ The lessons learned from the handling of that high mortality rate epidemic contribute to the call for taking innovative counter measures against emerging infectious diseases, including the use of mAbs. For example, an experimental mAb cocktail ZMapp was given special approval for compassionate use during the fast-moving epidemic. ZMapp is a combination of three mAbs (c13C6, c2G4, c4G7) optimized from two previous antibody cocktails (ZMab and MB-0033). ${ }^{113}$ ZMapp showed protective efficacy in a rhesus macaques challenge model. ${ }^{113}$ However, a randomized, controlled human trial of ZMapp plus the current standard of care did not meet the statistical threshold set for improved efficacy as compared with the current standard of care alone (NCT02363322) ${ }^{114-116}$. Efforts to isolate potent neutralizing antibodies against Ebola are ongoing. For example, potent neutralizing antibodies targeting the Ebola virus surface glycoprotein (EBOV GP) were isolated through sequential immunization of rhesus macaques and antigenspecific single B-cell sorting. ${ }^{117}$ Similarly, potent neutralizing antibodies targeting the Ebola EBOV GP were isolated from the peripheral B cells of a convalescent donor who survived the 2014 EBOV Zaire outbreak. ${ }^{118}$ These highly potent neutralizing mAbs could serve as promising candidates for prophylactic and therapeutic interventions against Ebola.

The outbreak of Zika in 2015-2016 and its association with congenital abnormalities also increased awareness of the urgent need to take measures against emerging infectious diseases. ${ }^{119}$ Similar to combating Ebola and other viral infections, development of vaccines is the top priority to protect the population from Zika infection. ${ }^{120}$ Antibody-based therapeutics are also proposed as an option for the treatment of Zika infection. ${ }^{23}$ For example, two antibodies with potent ZIKV-specific neutralization, isolated from a single patient, provided postexposure protection to mice in vivo. ${ }^{23}$ Structural studies revealed that Z23 and Z3L1 bound to tertiary epitopes in envelope protein domain I, II, or III, indicating potential targets for ZIKV-specific therapy. ${ }^{23}$

Rabies occurs worldwide and it is almost invariably fatal once clinical symptoms develop. ${ }^{121,122}$ Rabies is mostly preventable if post-exposure prophylaxis (PEP) is administered before clinical symptoms develop. PEP consists of thorough wound cleansing followed by immediate administration of rabies immune globulin (RIG), together with a full course of rabies vaccination. ${ }^{123}$ However, due to the lack of education and availability of RIGs and vaccines, it was estimated that global canine rabies causes about 59,000 deaths mostly in Asia and Africa. ${ }^{121}$ As the supply of human RIG (HRIG) and equine RIG (ERIG) is often limited, it is desirable to develop potent neutralizing human mAbs to replace RIGs. ${ }^{123}$ CL184 is mixture of two human mAbs:CR57 and CR4098. Mab CR57, which binds to an epitope of the rabies glycoprotein, was isolated from a EBV-transformed memory B cell from a human subject vaccinated with inactivated rabies virus. ${ }^{27,} 124,125$
MAbCR4098, which recognizes a non-overlapping epitope of mAbCR57, was isolated from phage-displayed antibody libraries constructed from PBMCs of rabies virus vaccinated human subjects. ${ }^{126}$ CL184 has been evaluated in multiple Phase $1 / 2$ clinical studies to be safe and efficacious. ${ }^{123,}{ }^{127-129}$ HuMab 17C7, also known as RAB1 which was generated from transgenic mice carrying human immunoglobulin, is another potent rabies virus neutralizing $\mathrm{mAb}$ that has been tested in multiple clinical trials in India (CTRI/2009/091/000465 and CTRI/2012/05/002709). ${ }^{130,} 131$ There are continuing efforts to identify more potent and broadly neutralizing mAbs against rabies. For example, two antibodies with potency and broad-spectrum reactivity, RVC20 and RVC58, were identified from immortalized B cells of vaccinated donors. ${ }^{132}$ RVC20 and RVC58 were able to neutralize all 35 strains of rabies virus in vitro. Furthermore, they showed higher potency and breadth compared to antibodies under clinical development, including CR57, CR4098, and RAB1. ${ }^{132}$

Hepatitis B can establish both acute and chronic infections that lead to serious liver disease. Maternal to fetal transmission is one important route keeping prevalence high in regions where the hepatitis B is endemic. Hepatitis B immunoglobulin antibody preparations are one form of countermeasure under investigation. ${ }^{133}$ mAbs are also under development to supplement the suite of tools available to control the spread of HBV and associated disease. ${ }^{134,135}$

Dengue. Dengue is the world's most prevalent mosquito-borne disease, with an estimated 390 million people each year becoming infected. $^{136}$ Severe dengue, associated with infection with different strains of the virus, is characterized by vascular permeability, bleeding from mucosa and intestinal tract, dengue shock syndrome, and acute renal failure. ${ }^{137}$ In contrast with HCMV where severe symptoms are accompanied by a detectable active phase, ${ }^{138}$ dengue symptoms often appear after the peak of viremia; ${ }^{139}$ therefore, an antibody applied for passive immunotherapy would have to be used before the onset of symptoms to be early enough to avoid viremia. Another difference between HCMV and dengue is that for HCMV, developing fetuses or infants and people with compromised immune systems are clearly at risk for the development of severe disease. ${ }^{43}$ In contrast, there are no clear prognostic indicators for susceptibility to severe dengue virus disease. Such prognostic indicators are necessary due to practical limitations on the number of people who can receive passive immunotherapy. Further, dengue antibodies at subneutralizing concentrations may enhance uptake of dengue virus in a way that dramatically aggravates symptoms (antibodydependent enhancement, ADE). ${ }^{136}$ Therefore, the development of vaccines has been the focus for dengue control. So far one vaccine has been approved, but the vaccine (CYD-TDV, Dengvaxia, Sanofi Pasteur) is less than ideal and better dengue vaccines are urgently needed. ${ }^{140}$

mAbs against dengue have been generated so their interaction with dengue could be analyzed to identify the virus' best target epitopes, a key first step in vaccine design. A summary of these epitopes and their associated antibodies is presented in several excellent reviews. ${ }^{136,141}$ The epitopes targeted by antibodies most effective at neutralizing dengue virus were grouped into broad classifications based on whether these epitopes were present in a single virion (epitopes on a monomer) or were composed of features on more than one virion (quaternary epitopes). Epitopes on a monomer were further grouped according by region of the dengue virion bound: prM protein, FLE (amino acids 98-113), BC loop E protein domain II (amino acids 73,78, and 79), or EDIII. Quaternary epitopes were also sub-divided into EDE epitopes (EDI, EDII, and EDIII); E protein epitopes (monomer EDI, EDI-EDII hinge, and EDIII; intact virion only); and E protein herring-bone epitope (EDI, EDI-EDII hinge, and EDIII). Although no dengue antibody therapeutics have reached the stage of clinical trials, some of 
broadly neutralizing antibodies have the potential to be developed into therapeutics against dengue infections. ${ }^{142-148}$

Dengue targeting antibodies at high concentration may enhance infection. Therefore, therapeutic antibodies need to be engineered to abolish the interaction of antibodies to the $\mathrm{Fc} \gamma \mathrm{Rs}$ on macrophages, thus preventing ADE. ${ }^{149}$ For example, a N297A mutation in the Fc region of D23-1G7C2 lgG1 was engineered to reduce the affinity of the $\operatorname{lgG} 1 \mathrm{Fc}$ region for $\mathrm{Fc} / \mathrm{Rs}$, resulting in a marked reduction in ADE activity in in vitro cell studies. ${ }^{150}$ In another study, dengue neutralizing mAbs targeting distinct epitopes on the four DENV serotypes were engineered to prevent FcyR binding by introducing LALA (L234A-L235A) mutations in the IgG1 Fc region. The LALA variant did not enhance infection and neutralized DENV in vitro and in vivo as postexposure therapy in a mouse model of lethal DENV infection. ${ }^{151}$

\section{Perspective}

Only one mAb, specific to RSV, has been approved for prophylaxis use of viral infections. Several challenges impede the progress of the many antiviral mAbs in the pipeline. One key challenge is the relatively small market for antibody treatments of viral diseases, and potentially higher cost associated with production of recombinant antibodies, as compared to small molecule antivirals.

Another key challenge is the competition of other forms of treatment and prevention. Vaccines are often still the best approach to control viral infections, often with benefits of lifelong immunity. Even after effective mAb therapies are developed, their widespread application may be impractical due to the high costs of conventional production compared to other countermeasures against disease from viral infections. One way to address the problem of the high cost of mAb therapies is to reduce the cost of production. For instance, production of mAbs in scFv or Fab form or as camelid nanobodies enables relatively inexpensive expression in prokaryotic systems. ${ }^{152}$ Another way to address the problem of high costs is financing through partnerships with traditional donors and newer funding sources such as the Gates Foundation. For example, development impact bonds have been tested as a way to eliminate rabies infection in dogs, in turn reducing demand for expensive treatments for humans. ${ }^{153}$

A third key challenge is the complexity of pathology, epidemiology, and immunology that can be associated with infection. The way kinetics of infection informs therapeutic strategy, for instance, explains why no dengue mAbs are in clinical trials and why vaccination is the preferred method to control influenza. For dengue and influenza $A$, symptoms often appear after the peak of viremia; ${ }^{139,} 154$ an antibody applied for passive immunotherapy would have to be used before the onset of symptoms to be early enough to avoid viremia. One potential solution is matching a therapeutic antibody with a rapid, point of care diagnostic test. The diagnostic could be used to identify patients with infection and susceptibility to severe disease who would benefit from passive immunotherapy with the therapeutic antibody. Finally, viruses can have complexity that prevents development of a single lasting treatment, for instance multiple strains, rapid evolution, and obscure mechanisms of infection and neutralization escape.

As discussed above, Fc region engineering has been shown effective for increasing the half-life of therapeutic antibodies, for instance the RSV mAb motavizumab YTE, and for preventing ADE through reduced FcR binding, as for dengue antibodies. The interactions of the $\mathrm{Fc}$ domain with diverse other receptors provides additional opportunities for engineering to optimize therapeutic efficacy of antibodies. The advantages and disadvantages of engineering approaches was recently reviewed by Bournazos and Ravetch. ${ }^{155}$

Passive transfer of antibodies for the prevention and treatment of viral infections is easy to manage, but the high cost associated with antibody therapies is prohibitive in prophylactic use of antibodies for intractable viruses such as HIV and influenza A virus for a large population, particularly in low-resource areas. ${ }^{156}$ One alternative to passive administration of antibody therapies involves the delivery of transgenes encoding well characterized neutralizing antibodies by a vector. The transgenes direct the expression of antibodies in non-hematopoietic cells, which then secrete mAbs into circulation. It has been demonstrated that intramuscular delivery by electroporation of synthetic DNA plasmids engineered to express modified human mAbs against multiple DENV serotypes confers protection against DENV disease and prevents ADE of disease in mice. ${ }^{157}$ More work is needed before clinical applications, but vector delivery of prophylactic or therapeutic antibodies against viral infections is a promising alternative to the current practice of passive transfer.

\section{ACKNOWLEDGEMENTS}

This work was partially funded by grants from Merck, the Texas Emerging Technology Fund, and The Welch Foundation Grant AU00024 (Z.A.).

\section{AUTHOR CONTRIBUTIONS}

All authors contributed extensively to the work of writing and editing this manuscript.

\section{ADDITIONAL INFORMATION}

Competing interests: The authors declare no competing financial interest.

Publisher's note: Springer Nature remains neutral with regard to jurisdictional claims in published maps and institutional affiliations.

\section{REFERENCES}

1. Ehrlich, P. Partial cell functions-Nobel lecture, December 11, 1908 in Physiology or Medicine: including Presentation Speeches and Laureates' Biographies. 304-320 (Elsevier Publisher, 1908).

2. Winau, F., Westphal, O. \& Winau, R. Paul Ehrlich--in search of the magic bullet. Microbes Infect. 6, 786-789 (2004).

3. Stangel, M. \& Pul, R. Basic principles of intravenous immunoglobulin (IVlg) treatment. J. Neurol. 253, V18-24 (2006).

4. Kohler, G. \& Milstein, C. Continuous cultures of fused cells secreting antibody of predefined specificity. Nature 256, 495-497 (1975).

5. Throsby, M. et al. Heterosubtypic neutralizing monoclonal antibodies crossprotective against $\mathrm{H} 5 \mathrm{~N} 1$ and $\mathrm{H} 1 \mathrm{~N} 1$ recovered from human IgM+memory B cells. PLOS ONE 3, e3942 (2008).

6. Meng, W. et al. Rapid generation of human-like neutralizing monoclonal antibodies in urgent preparedness for influenza pandemics and virulent infectious diseases. PLOS ONE 8, e66276 (2013).

7. Harvey, B. R. et al. Anchored periplasmic expression, a versatile technology for the isolation of high-affinity antibodies from Escherichia coli-expressed libraries. Proc. Natl Acad. Sci. U.S.A. 101, 9193-9198 (2004).

8. Bowley, D. R., Labrijn, A. F., Zwick, M. B. \& Burton, D. R. Antigen selection from an HIV-1 immune antibody library displayed on yeast yields many novel antibodies compared to selection from the same library displayed on phage. Protein Eng. Des. Sel. 20, 81-90 (2007).

9. Smith, E. S. \& Zauderer, M. In Therapeutic Monoclonal Antibodies: from bench to Clinic (ed. Z. An) 283-307 (John Wiley \& Sons, 2009).

10. Huang, J. et al. Isolation of human monoclonal antibodies from peripheral blood B cells. Nat. Protoc. 8, 1907-1915 (2013).

11. Walker, L. M. et al. Broad and potent neutralizing antibodies from an African donor reveal a new HIV-1 vaccine target. Science 326, 285-289 (2009).

12. Scheid, J. F. et al. Broad diversity of neutralizing antibodies isolated from memory B cells in HIV-infected individuals. Nature 458, 636-640 (2009).

13. Traggiai, E. et al. An efficient method to make human monoclonal antibodies from memory B cells: potent neutralization of SARS coronavirus. Nat. Med. 10, 871-875 (2004).

14. Reddy, S. T. et al. Monoclonal antibodies isolated without screening by analyzing the variable-gene repertoire of plasma cells. Nat. Biotechnol. 28, 965-969 (2010). 
15. Wrammert, J. et al. Rapid cloning of high-affinity human monoclonal antibodies against influenza virus. Nature 453, 667-671 (2008).

16. Meng, W. et al. Efficient generation of monoclonal antibodies from single rhesus macaque antibody secreting cells. MAbs 7, 707-718 (2015).

17. Cheung, W. C. et al. A proteomics approach for the identification and cloning of monoclonal antibodies from serum. Nat. Biotechnol., doi:nbt.2167 [pii], 10.1038/ nbt.2167 (2012).

18. Wine, $\mathrm{Y}$. et al. Molecular deconvolution of the monoclonal antibodies that comprise the polyclonal serum response. Proc. Natl Acad. Sci. U.S.A. 110, 2993-2998 (2013).

19. McDaniel, J. R., DeKosky, B. J., Tanno, H., Ellington, A. D. \& Georgiou, G. Ultrahigh-throughput sequencing of the immune receptor repertoire from millions of lymphocytes. Nat. Protoc. 11, 429-442 (2016).

20. DeKosky, B. J. et al. In-depth determination and analysis of the human paired heavy- and light-chain antibody repertoire. Nat. Med. 21, 86-91 (2015).

21. Miller, M. D. et al. A human monoclonal antibody neutralizes diverse HIV-1 isolates by binding a critical gp41 epitope. Proc. Natl Acad. Sci. U.S.A. 102, 14759-14764 (2005).

22. Corti, D. \& Lanzavecchia, A. Efficient methods to isolate human monoclonal antibodies from memory b cells and plasma cells. Microbiol. Spectr. 2, doi:10.1128/microbiolspec.AID-0018-2014 (2014).

23. Wang, Q. et al. Molecular determinants of human neutralizing antibodies isolated from a patient infected with Zika virus. Sci, Transl. Med. 8, 369ra179, doi:10.1126/scitranslmed.aai8336 (2016).

24. Gilman, M. S. A. et al. Rapid profiling of RSV antibody repertoires from the memory B cells of naturally infected adult donors. Sci. Immunol. 1, doi:10.1126/ sciimmunol.aaj1879 (2016).

25. Scherer, E. M. et al. Characteristics of memory B cells elicited by a highly efficacious HPV vaccine in subjects with no pre-existing immunity. PLoS Pathog. 10, e1004461 (2014).

26. Sundling, C. et al. Single-cell and deep sequencing of IgG-switched macaque B cells reveal a diverse Ig repertoire following immunization. J. Immunol. 192, 3637-3644 (2014).

27. Ueki, Y. et al. Clonal analysis of a human antibody response. Quantitation of precursors of antibody-producing cells and generation and characterization of monoclonal $\lg \mathrm{M}, \lg G$, and $\lg \mathrm{A}$ to rabies virus. J. Exp. Med. 171, 19-34 (1990).

28. Bernasconi, N. L., Traggiai, E. \& Lanzavecchia, A. Maintenance of serological memory by polyclonal activation of human memory B cells. Science 298, 2199-2202 (2002).

29. Corti, D. et al. A neutralizing antibody selected from plasma cells that binds to group 1 and group 2 influenza A hemagglutinins. Science 333, 850-856 (2011).

30. Smith, K. et al. Rapid generation of fully human monoclonal antibodies specific to a vaccinating antigen. Nat. Protoc. 4, 372-384 (2009).

31. Wrammert, J. et al. Rapid and massive virus-specific plasmablast responses during acute dengue virus infection in humans. J. Virol. 86, 2911-2918 (2012).

32. Nakamura, G. et al. An in vivo human-plasmablast enrichment technique allows rapid identification of therapeutic influenza A antibodies. Cell Host Microbe. 14, 93-103 (2013).

33. Dejnirattisai, W. et al. A new class of highly potent, broadly neutralizing antibodies isolated from viremic patients infected with dengue virus. Nat. Immunol. 16, 170-177 (2015)

34. Wrammert, J. et al. Broadly cross-reactive antibodies dominate the human B cell response against 2009 pandemic H1N1 influenza virus infection. J. Exp. Med. 208, 181-193 (2011).

35. Sundling, C., Phad, G., Douagi, I., Navis, M. \& Karlsson Hedestam, G. B. Isolation of antibody $V(D) J$ sequences from single cell sorted rhesus macaque $B$ cells. $J$. Immunol. Methods 386, 85-93 (2012).

36. Demberg, T. et al. Dynamics of memory B-cell populations in blood, lymph nodes, and bone marrow during antiretroviral therapy and envelope boosting in simian immunodeficiency virus SIVmac251-infected rhesus macaques. J. Virol. 86, 12591-12604 (2012).

37. Jin, A. et al. A rapid and efficient single-cell manipulation method for screening antigen-specific antibody-secreting cells from human peripheral blood. Nat. Med. 15, 1088-1092 (2009).

38. Sato, S. et al. Proteomics-directed cloning of circulating antiviral human monoclonal antibodies. Nat. Biotechnol. 30, 1039-1043 (2012).

39. Boutz, D. R. et al. Proteomic identification of monoclonal antibodies from serum. Anal. Chem. 86, 4758-4766 (2014).

40. $\mathrm{Wu}, \mathrm{X}$. et al. Focused evolution of HIV-1 neutralizing antibodies revealed by structures and deep sequencing. Science 333, 1593-1602 (2011).

41. Zhu, J. et al. Mining the antibodyome for HIV-1-neutralizing antibodies with next-generation sequencing and phylogenetic pairing of heavy/light chains. Proc. Natl Acad. Sci. USA, doi:10.1073/pnas.1219320110 (2013).
42. Dekosky, B. J. et al. High-throughput sequencing of the paired human immunoglobulin heavy and light chain repertoire. Nat. Biotechnol., doi:10.1038/ nbt.2492 (2013).

43. Fu, T. M., An, Z. \& Wang, D. Progress on pursuit of human cytomegalovirus vaccines for prevention of congenital infection and disease. Vaccine 32, 2525-2533 (2014).

44. Wang, D. et al. A replication-defective human cytomegalovirus vaccine for prevention of congenital infection. Sci. Transl. Med. 8, 362ra145 (2016).

45. Komatsu, T. E., Pikis, A., Naeger, L. K. \& Harrington, P. R. Resistance of human cytomegalovirus to ganciclovir/valganciclovir: a comprehensive review of putative resistance pathways. Antiviral Res. 101, 12-25 (2014).

46. Houldcroft, C. J. et al. Detection of low frequency multi-drug resistance and novel putative maribavir resistance in immunocompromised pediatric patients with cytomegalovirus. Front. Microbiol. 7, 1317 (2016).

47. Revello, M. G. et al. A randomized trial of hyperimmune globulin to prevent congenital cytomegalovirus. N. Engl. J. Med. 370, 1316-1326 (2014).

48. Dole, K. et al. A first-in-human study to assess the safety and pharmacokinetics of monoclonal antibodies against human cytomegalovirus in healthy volunteers. Antimicrob. Agents Chemother., doi:10.1128/AAC.02698-15 (2016).

49. Ishida, J. H. et al. Phase 1 randomized, double-blind, placebo-controlled study of RG7667, an anticytomegalovirus combination monoclonal antibody therapy, in healthy adults. Antimicrob. Agents Chemother. 59, 4919-4929 (2015).

50. Freed, D. C. et al. Pentameric complex of viral glycoprotein $\mathrm{H}$ is the primary target for potent neutralization by a human cytomegalovirus vaccine. Proc. Natl Acad. Sci. U.S.A. 110, E4997-5005 (2013).

51. Ohlin, M. \& Soderberg-Naucler, C. Human antibody technology and the development of antibodies against cytomegalovirus. Mol. Immunol., doi:10.1016/j. molimm.2015.02.026 (2015).

52. Macagno, A. et al. Isolation of human monoclonal antibodies that potently neutralize human cytomegalovirus infection by targeting different epitopes on the $\mathrm{gH} / \mathrm{gL} / \mathrm{UL} 128-131$ A complex. J. Virol. 84, 1005-1013 (2010).

53. Patel, H. D. et al. In vitro characterization of human cytomegalovirus-targeting therapeutic monoclonal antibodies LJP538 and LJP539. Antimicrob. Agents Chemother. 60, 4961-4971 (2016).

54. Novartis. A. Multi-center, Randomized, Double-blind, Placebo Controlled, Study to Evaluate the Efficacy and Safety of CSJ148 Compared to Placebo to Prevent Human Cytomegalovirus (HCMV) Replication in Stem Cell Transplant Patients. NCT02268526 (ClinicalTrials.gov, 2016).

55 . Li, B. et al. In vitro affinity maturation of a natural human antibody overcomes a barrier to in vivo affinity maturation. MAbs 6, 437-445 (2014).

56. Borucki, M. J. et al. A phase II, double-masked, randomized, placebo-controlled evaluation of a human monoclonal anti-Cytomegalovirus antibody (MSL-109) in combination with standard therapy versus standard therapy alone in the treatment of AIDS patients with Cytomegalovirus retinitis. Antiviral Res. 64, 103-111 (2004).

57. Manley, K. et al. Human cytomegalovirus escapes a naturally occurring neutralizing antibody by incorporating it into assembling virions. Cell Host Microbe 10, 197-209 (2011).

58. Ishida, J. H. et al. Phase 2 randomized, double-blind, placebo-controlled trial of RG7667, a combination monoclonal antibody, for prevention of cytomegalovirus infection in high-risk kidney transplant recipients. Antimicrob. Agents Chemother. (2016).

59. Mc Mahon, A. \& Martin-Loeches, I. The pharmacological management of severe influenza infection - 'existing and emerging therapies'. Expert Rev. Clin. Pharmacol. 10, 81-95 (2017).

60. Pappas, L. et al. Rapid development of broadly influenza neutralizing antibodies through redundant mutations. Nature 516, 418-422 (2014).

61. Krammer, F. Novel universal influenza virus vaccine approaches. Curr. Opin. Virol. 17, 95-103 (2016)

62. Gupta, P. et al. Preclinical pharmacokinetics of MHAA4549A, a human monoclonal antibody to influenza $A$ virus, and the prediction of its efficacious clinical dose for the treatment of patients hospitalized with influenza A. MAbs 8 , 991-997 (2016).

63. Lim, J. J. et al. Two phase 1, randomized, double-blind, placebo-controlled, single-ascending-dose studies to investigate the safety, tolerability, and pharmacokinetics of an anti-influenza A virus monoclonal antibody, MHAA4549A, in healthy volunteers. Antimicrob. Agents Chemother. 60, 5437-5444 (2016).

64. Genentech. A. Study of MHAA4549A as Monotherapy for Acute Uncomplicated Seasonal Influenza A in Otherwise Healthy Adults. NCT02623322 (ClinicalTrials. gov, 2016).

65. Genentech. A. Study of MHAA4549A in Combination with Oseltamivir Versus Oseltamivir in Participants with Severe Influenza A Infection. NCT02293863 (ClinicalTrials.gov, 2016).

66. Naik, G. Scientists' elusive goal: reproducing study resutls. (Wall Street Journal, 2015). 
67. Baranovich, T. et al. The hemagglutinin stem-binding monoclonal antibody VIS410 controls influenza virus-induced acute respiratory distress syndrome. Antimicrob. Agents Chemother. 60, 2118-2131 (2016).

68. Wollacott, A. M. et al. Safety and upper respiratory pharmacokinetics of the hemagglutinin stalk-binding antibody VIS410 support treatment and prophylaxis based on population modeling of seasonal influenza A outbreaks. EBioMedicine 5, 147-155, doi:10.1016/j.ebiom.2016.02.021 (2016).

69. Visterra. A. Phase 2a Double-blind, Placebo-controlled Study to Assess the Safety and Tolerability of a Single Intravenous Dose of VIS410 in Subjects with Uncomplicated Influenza A Infection. NCT02989194 (ClinicalTrials.gov, 2016).

70. Ekiert, D. C. et al. Antibody recognition of a highly conserved influenza virus epitope. Science 324, 246-251 (2009).

71. NIAID. Randomized, Double-Blind, Placebo-Controlled, Phase 2 Study in Healthy Volunteers to Evaluate the Efficacy and Safety of CR6261 in an H1N1 Influenza Healthy Human Challenge Model. NCT02371668 (ClinicalTrials.gov, 2016)

72. Ekiert, D. C. et al. A highly conserved neutralizing epitope on group 2 influenza A viruses. Science 333, 843-850 (2011).

73. Crucell. Randomised, Double-Blind, Placebo-Controlled, Phase lla Study in Healthy Volunteers to Evaluate the Protective Efficacy and Safety of CR8020 in an Influenza Challenge Model. NCT01938352 (ClinicalTrials.gov, 2014).

74. Tharakaraman, K., Subramanian, V., Cain, D., Sasisekharan, V. \& Sasisekharan, R. Broadly neutralizing influenza hemagglutinin stem-specific antibody CR8020 targets residues that are prone to escape due to host selection pressure. Cell Host Microbe 15, 644-651 (2014).

75. Grandea, A. G. 3rd et al. Human antibodies reveal a protective epitope that is highly conserved among human and nonhuman influenza A viruses. Proc. Nat Acad. Sci. U.S.A. 107, 12658-12663 (2010).

76. Ramos, E. L. et al. Efficacy and safety of treatment with an anti-m2e monoclonal antibody in experimental human influenza. J. Infect. Dis. 211, 1038-1044 (2015).

77. Smith, S. A. \& Derdeyn, C. A. Harnessing the protective potential of HIV-1 neutralizing antibodies. F1000Research 5, doi:10.12688/f1000research.7254.1 (2016).

78. Klein, F. et al. Antibodies in HIV-1 vaccine development and therapy. Science 341, 1199-1204 (2013).

79. CytoDyn. A Randomized, Double-blind, Placebo-controlled Trial, Followed by Single-arm Treatment of PRO 140 in Combination w/ Optimized Background Therapy in Treatment-Experienced HIV Subjects (PRO 140). NCT02483078 (ClinicalTrials.gov, 2016).

80. Escolano, A., Dosenovic, P. \& Nussenzweig, M. C. Progress toward active or passive HIV-1 vaccination. J. Exp. Med. doi:10.1084/jem.20161765 (2016).

81. Gray, G. E., Laher, F., Lazarus, E., Ensoli, B. \& Corey, L. Approaches to preventative and therapeutic HIV vaccines. Curr. Opin. Virol. 17, 104-109 (2016).

82. Marasco, W. A. \& Sui, J. The growth and potential of human antiviral monoclonal antibody therapeutics. Nat. Biotechnol. 25, 1421-1434 (2007).

83. Zhou, T. et al. Structural basis for broad and potent neutralization of HIV-1 by antibody VRC01. Science 329, 811-817 (2010).

84. Scharf, L. et al. Structural basis for germline antibody recognition of HIV-1 immunogens. Elife 5, doi:10.7554/eLife.13783 (2016).

85. Ledgerwood, J. E. et al. Safety, pharmacokinetics and neutralization of the broadly neutralizing HIV-1 human monoclonal antibody VRCO1 in healthy adults. Clin. Exp. Immunol. 182, 289-301 (2015).

86. Bar, K. J. et al. Effect of HIV antibody VRC01 on viral rebound after treatment interruption. N. Engl. J. Med. 375, 2037-2050 (2016).

87. NIAID. Evaluating the Safety and Efficacy of the VRC01 Antibody in Reducing Acquisition of HIV-1 Infection Among Men and Transgender Persons Who Have Sex with Men. NCT02716675 (ClinicalTrials.gov, 2016).

88. NIAID. Evaluating the Safety and Efficacy of the VRC01 Antibody in Reducing Acquisition of HIV-1 Infection in Women. NCT02568215 (ClinicalTrials.gov, 2016).

89. NIAID. Safety and Therapeutic Efficacy of the VRC01 Antibody in Patients Who Initiated Antiretroviral Therapy During Early Acute HIV Infection. NCT02664415 (ClinicalTrials.gov, 2016).

90. Scheid, J. F. et al. Sequence and structural convergence of broad and potent HIV antibodies that mimic CD4 binding. Science 333, 1633-1637 (2011).

91. Shingai, M. et al. Antibody-mediated immunotherapy of macaques chronically infected with SHIV suppresses viraemia. Nature 503, 277-280 (2013)

92. Caskey, M. et al. Viraemia suppressed in HIV-1-infected humans by broadly neutralizing antibody 3BNC117. Nature 522, 487-491 (2015).

93. Scheid, J. F. et al. HIV-1 antibody 3BNC117 suppresses viral rebound in humans during treatment interruption. Nature 535, 556-560 (2016).

94. Schoofs, T. et al. HIV-1 therapy with monoclonal antibody 3BNC117 elicits host immune responses against HIV-1. Science 352, 997-1001 (2016).

95. University, R. 3BNC117 and 10-1074 in HIV Uninfected Adults. NCT02824536 (ClinicalTrials.gov, 2016).

96. University, R. 3BNC117 and 10-1074 in HIV-Infected Individuals. NCT02825797 (ClinicalTrials.gov, 2016).
97. University, R. A Phase I/II Single Site Open Label Trial of the Safety and Antiviral Activity of C2F5, C2G12, and C4E10 Monoclonal Antibody Infusions in WellSuppressed HAART-Treated Individuals Treated During Acute and Early HIV-1 Infection. NCT00219986 (ClinicalTrials.gov, 2007).

98. Murga, J. D., Franti, M., Pevear, D. C., Maddon, P. J. \& Olson, W. C. Potent antiviral synergy between monoclonal antibody and small-molecule CCR5 inhibitors of human immunodeficiency virus type 1. Antimicrob. Agents Chemother. 50, 3289-3296 (2006)

99. Jacobson, J. M. et al. Phase 2a study of the CCR5 monoclonal antibody PRO 140 administered intravenously to HIV-infected adults. Antimicrob. Agents Chemother. 54, 4137-4142 (2010).

100. Henrich, T. J. \& Kuritzkes, D. R. HIV-1 entry inhibitors: recent development and clinical use. Curr. Opin. Virol. 3, 51-57 (2013).

101. Pace, C. S. et al. Bispecific antibodies directed to CD4 domain 2 and HIV envelope exhibit exceptional breadth and picomolar potency against HIV-1. Proc. Natl Acad. Sci. U.S.A. 110, 13540-13545 (2013).

102. Sun, M. et al. Rational design and characterization of the novel, broad and potent bispecific HIV-1 neutralizing antibody iMabm36. J. Acquir. Immune Defic. Syndr. 66, 473-483 (2014).

103. McLellan, J. S. et al. Structural basis of respiratory syncytial virus neutralization by motavizumab. Nat. Struct. Mol. Biol. 17, 248-250 (2010).

104. Mejias, A. \& Ramilo, O. New options in the treatment of respiratory syncytial virus disease. J. Infect. 71, S80-87 (2015).

105. $\mathrm{Wu}, \mathrm{H}$. et al. Ultra-potent antibodies against respiratory syncytial virus: effects of binding kinetics and binding valence on viral neutralization. J. Mol. Biol. 350, 126-144 (2005).

106. Carbonell-Estrany, X. et al. Motavizumab for prophylaxis of respiratory syncytial virus in high-risk children: a noninferiority trial. Pediatrics 125, e35-51 (2010).

107. Robbie, G. J. et al. A novel investigational Fc-modified humanized monoclonal antibody, motavizumab-YTE, has an extended half-life in healthy adults. Antimicrob. Agents Chemother. 57, 6147-6153 (2013).

108. Griffin, M. P. et al. Safety, tolerability, and pharmacokinetics of the respiratory syncytial virus-prefusion F-targeting monoclonal antibody with an extended half-life, MEDI8897, in healthy adults. Antimicrob Agents Chemother, doi:10.1128/ AAC.01714-16 (2016).

109. Medlmmune. A. Phase $2 \mathrm{~b}$ Randomized, Double-Blind, Placebo-controlled Study to Evaluate the Safety and Efficacy of MEDI8897, a Monoclonal Antibody with an Extended Half-life Against Respiratory Syncytial Virus, in Healthy Preterm Infants. NCT02878330 (ClinicalTrials.gov, 2016).

110. Regeneron. A. Phase 3, Randomized, Double-Blind, Placebo-Controlled Study Evaluating the Efficacy and Safety of a Human Monoclonal Antibody, REGN2222, for the Prevention of Medically Attended RSV Infection in Preterm Infants. NCT02325791 (ClinicalTrials.gov, 2016).

111. Broadbent, L., Groves, H., Shields, M. D. \& Power, U. F. Respiratory syncytial virus, an ongoing medical dilemma: an expert commentary on respiratory syncytial virus prophylactic and therapeutic pharmaceuticals currently in clinical trials. Influenza Other Respir. Viruses 9, 169-178 (2015).

112. Kaner, J. \& Schaack, S. Understanding Ebola: the 2014 epidemic. Global. Health 12, 53 (2016).

113. Qiu, X. et al. Reversion of advanced Ebola virus disease in nonhuman primates with ZMapp. Nature 514, 47-53 (2014).

114. Dodd, L. E. et al. Design of a randomized controlled trial for Ebola virus disease medical countermeasures: PREVAIL II, the Ebola MCM Study. J. Infect. Dis. 213 1906-1913 (2016)

115. Group, P. I. W. \& Multi-National, P. I. I. S. T. A randomized, controlled trial of ZMapp for Ebola virus infection. N. Engl. J. Med. 375, 1448-1456 (2016).

116. Cardile, A. P., Downey, L. G., Wiseman, P. D., Warren, T. K. \& Bavari, S. Antiviral therapeutics for the treatment of Ebola virus infection. Curr. Opin. Pharmacol. 30, 138-143 (2016).

117. Zhang, Q. et al. Potent neutralizing monoclonal antibodies against Ebola virus infection. Sci. Rep. 6, 25856 (2016).

118. Bornholdt, Z. A. et al. Isolation of potent neutralizing antibodies from a survivor of the 2014 Ebola virus outbreak. Science 351, 1078-1083 (2016).

119. Krauer, F. et al. zika virus infection as a cause of congenital brain abnormalities and Guillain-Barre syndrome: systematic review. PLoS Med. 14, e1002203 (2017).

120. Dawes, B. E. et al. Research and development of Zika virus vaccines. Npj Vaccines 1, 16007, doi:10.1038/npjvaccines.2016.7 (2016)

121. Hampson, K. et al. Estimating the global burden of endemic canine rabies. PLoS Negl. Trop. Dis. 9, e0003709 (2015).

122. Jackson, A. C. Human rabies: a 2016 update. Curr. Infect. Dis. Rep. 18, 38 (2016)

123. Bakker, A. B. et al. First administration to humans of a monoclonal antibody cocktail against rabies virus: safety, tolerability, and neutralizing activity. Vaccine 26, 5922-5927 (2008).

124. Dietzschold, B. et al. Biological characterization of human monoclonal antibodies to rabies virus. J. Virol. 64, 3087-3090 (1990). 
125. Marissen, W. E. et al. Novel rabies virus-neutralizing epitope recognized by human monoclonal antibody: fine mapping and escape mutant analysis. J. Virol. 79, 4672-4678 (2005).

126. Bakker, A. B. et al. Novel human monoclonal antibody combination effectively neutralizing natural rabies virus variants and individual in vitro escape mutants. J. Virol. 79, 9062-9068 (2005).

127. A Single-blind, Randomized, Monocentric Phase II Trial to Explore the Safety and Rabies-neutralizing Activity of Combined Administration of CL184 and Rabies Vaccine Versus Human Rabies Immune Globulin Plus Rabies Vaccine in Simulated Rabies Post-exposure Prophylaxis in Children and Adolescents. NCT00708084 (ClinicalTrials.gov, 2012).

128. A Randomized, Single-blind, Controlled, Monocentric Phase II Trial to Compare the Safety and Neutralizing Activity of Simulated Rabies Post-exposure Prophylaxis With CL184 in Combination With Rabies Vaccine vs. HRIG or Placebo in Combination With Rabies Vaccine in Healthy Adult Subjects. NCT00656097 (ClinicalTrials.gov, 2011).

129. Rabies Virus Neutralizing Activity and Safety of CL184, a Monoclonal Antibody Cocktail, in Simulated Rabies Post-Exposure Prophylaxis in Healthy Adults. NCT01228383 (ClinicalTrials.gov, 2013).

130. Sloan, S. E. et al. Identification and characterization of a human monoclonal antibody that potently neutralizes a broad panel of rabies virus isolates. Vaccine 25, 2800-2810 (2007).

131. Wang, Y. et al. G glycoprotein amino acid residues required for human monoclonal antibody RAB1 neutralization are conserved in rabies virus street isolates. Antiviral Res. 91, 187-194 (2011).

132. De Benedictis, P. et al. Development of broad-spectrum human monoclonal antibodies for rabies post-exposure prophylaxis. EMBO Mol. Med. 8, 407-421 (2016).

133. Hospital, B. D. A Study of the Interruption on the Mother-to-child Transmission of Hepatitis B Virus (HBV MTCT)in Newborns at High Risk. ClinicalTrials.gov, NCT02901418 (2016)

134. Zhang, T. Y. et al. Prolonged suppression of HBV in mice by a novel antibody that targets a unique epitope on hepatitis B surface antigen. Gut $\mathbf{6 5}, 658-671$ (2016).

135. Wang, W. et al. A human monoclonal antibody against small envelope protein of hepatitis B virus with potent neutralization effect. MAbs 8, 468-477 (2016).

136. Fibriansah, G. \& Lok, S. M. The development of therapeutic antibodies against dengue virus. Antiviral Res. 128, 7-19 (2016).

137. Thomas, S. J. \& Endy, T. P. Critical issues in dengue vaccine development. Curr. Opin. Infect. Dis. 24, 442-450 (2011).

138. Varani, S. \& Landini, M. P. Cytomegalovirus-induced immunopathology and its clinical consequences. Herpesviridae 2, 6 (2011).

139. de Oliveira Poersch, C. et al. Dengue virus infections: comparison of methods for diagnosing the acute disease. J. Clin. Virol. 32, 272-277 (2005).

140. Deen, J., Weber, M. W. \& Jaenisch, T. Dengue in the context of the integrated management of childhood illness. PLoS Negl. Trop. Dis. 10, e0004838 (2016).

141. Screaton, G., Mongkolsapaya, J., Yacoub, S. \& Roberts, C. New insights into the immunopathology and control of dengue virus infection. Nat. Rev. Immunol. 15, 745-759 (2015).

142. Fibriansah, G. et al. DENGUE VIRUS. Cryo-EM structure of an antibody that neutralizes dengue virus type 2 by locking E protein dimers. Science 349, 88-91 (2015).
143. Fibriansah, G. et al. A potent anti-dengue human antibody preferentially recognizes the conformation of $E$ protein monomers assembled on the virus surface. EMBO Mol. Med. 6, 358-371 (2014).

144. Lai, C. J. et al. Epitope determinants of a chimpanzee dengue virus type 4 (DENV-4)-neutralizing antibody and protection against DENV-4 challenge in mice and rhesus monkeys by passively transferred humanized antibody. J. Virol. 81, 12766-12774 (2007).

145. Shrestha, B. et al. The development of therapeutic antibodies that neutralize homologous and heterologous genotypes of dengue virus type 1. PLoS Pathog. 6, e1000823 (2010)

146. Teoh, E. P. et al. The structural basis for serotype-specific neutralization of dengue virus by a human antibody. Sci. Transl. Med. 4, 139ra183 (2012).

147. Smith, S. A. et al. The potent and broadly neutralizing human dengue virusspecific monoclonal antibody $1 \mathrm{C} 19$ reveals a unique cross-reactive epitope on the bc loop of domain II of the envelope protein. mBio 4, e00873-00813 (2013).

148. Robinson, L. N. et al. Structure-guided design of an anti-dengue antibody directed to a non-immunodominant epitope. Cell 162, 493-504 (2015).

149. Williams, K. L. et al. Therapeutic efficacy of antibodies lacking Fcgamma receptor binding against lethal dengue virus infection is due to neutralizing potency and blocking of enhancing antibodies [corrected]. PLoS Pathog. 9, e1003157 (2013).

150. Ramadhany, R. et al. Antibody with an engineered Fc region as a therapeutic agent against dengue virus infection. Antiviral Res. 124, 61-68 (2015).

151. Beltramello, M. et al. The human immune response to Dengue virus is dominated by highly cross-reactive antibodies endowed with neutralizing and enhancing activity. Cell Host Microbe 8, 271-283 (2010).

152. Both, L. et al. Monoclonal antibodies for prophylactic and therapeutic use against viral infections. Vaccine 31, 1553-1559 (2013).

153. Welburn, S. C., Coleman, P. G. \& Zinsstag, J. Rabies control: could innovative financing break the deadlock? Front. Vet. Sci. 4, 32 (2017).

154. Baccam, P., Beauchemin, C., Macken, C. A., Hayden, F. G. \& Perelson, A. S. Kinetics of influenza A virus infection in humans. J. Virol. 80, 7590-7599 (2006).

155. Bournazos, S. \& Ravetch, J. V. Anti-retroviral antibody FcgammaR-mediated effector functions. Immunol. Rev. 275, 285-295 (2017).

156. Deal, C. E. \& Balazs, A. B. Engineering humoral immunity as prophylaxis or therapy. Curr. Opin. Immunol. 35, 113-122 (2015).

157. Flingai, S. et al. Protection against dengue disease by synthetic nucleic acid antibody prophylaxis/immunotherapy. Sci. Rep. 5, 12616 (2015)

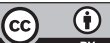

Open Access This article is licensed under a Creative Commons Attribution 4.0 International License, which permits use, sharing, adaptation, distribution and reproduction in any medium or format, as long as you give appropriate credit to the original author(s) and the source, provide a link to the Creative Commons license, and indicate if changes were made. The images or other third party material in this article are included in the article's Creative Commons license, unless indicated otherwise in a credit line to the material. If material is not included in the article's Creative Commons license and your intended use is not permitted by statutory regulation or exceeds the permitted use, you will need to obtain permission directly from the copyright holder. To view a copy of this license, visit http://creativecommons. org/licenses/by/4.0/.

(c) The Author(s) 2017 